\title{
Conservation and monitoring of invertebrates in terrestrial protected areas
}

\author{
Authors: \\ Melodie A. McGeoch ${ }^{1}$ \\ Hendrik Sithole ${ }^{2}$ \\ Michael J. Samways ${ }^{3}$ \\ John P. Simaika ${ }^{3}$ \\ James S. Pryke ${ }^{3}$ \\ Mike Picker ${ }^{4}$ \\ Charmaine Uys ${ }^{4}$ \\ Adrian J. Armstrong \\ Ansie S. Dippenaar- \\ Schoeman $^{6,7}$ \\ Ian A. Engelbrecht ${ }^{8}$ \\ Brigitte Braschler ${ }^{9}$ \\ Michelle Hamer ${ }^{10}$ \\ Affiliations: \\ ${ }^{1}$ Cape Research Centre, \\ South African National \\ Parks, Cape Town, \\ South Africa \\ ${ }^{2}$ Savanna and Arid Parks, \\ South African National Parks, \\ Kimberley, South Africa \\ ${ }^{3}$ Department of Conservation \\ Ecology and Entomology, \\ Stellenbosch University, \\ South Africa \\ ${ }^{4}$ Zoology Department, \\ University of Cape Town, \\ South Africa \\ ${ }^{5}$ Ezemvelo KZN Wildlife, \\ Pietermaritzburg, South Africa \\ ${ }^{6}$ ARC-Plant Protection \\ Research Institute, Pretoria, \\ South Africa \\ ${ }^{7}$ Department of Zoology and \\ Entomology, University of \\ Pretoria, South Africa \\ ${ }^{8}$ Gauteng Department of \\ Agriculture, Conservation and \\ Environment, Johannesburg, \\ South Africa \\ ${ }^{9}$ Centre for Invasion Biology, \\ Department of Botany \\ and Zoology, Stellenbosch \\ University, South Africa \\ ${ }^{10}$ Biosystematics Division, \\ South African National \\ Biodiversity Institute, \\ South Africa \\ Correspondence to: \\ Melodie McGeoch \\ Email: \\ melodiem@sanparks.org \\ Postal address: \\ PO Box 216, Steenberg 7947 \\ South Africa
}

Invertebrates constitute a substantial proportion of terrestrial and freshwater biodiversity and are critical to ecosystem function. However, their inclusion in biodiversity monitoring and conservation planning and management has lagged behind better-known, more widely appreciated taxa. Significant progress in invertebrate surveys, systematics and bioindication, both globally and locally, means that their use in biodiversity monitoring and conservation is becoming increasingly feasible. Here we outline challenges and solutions to the integration of invertebrates into biodiversity management objectives and monitoring in protected areas in South Africa. We show that such integration is relevant and possible, and assess the relative suitability of seven key taxa in this context. Finally, we outline a series of recommendations for mainstreaming invertebrates in conservation planning, surveys and monitoring in and around protected areas.

Conservation implications: Invertebrates constitute a substantial and functionally significant component of terrestrial biodiversity and are valuable indicators of environmental condition. Although consideration of invertebrates has historically been neglected in conservation planning and management, substantial progress with surveys, systematics and bioindication means that it is now both feasible and advisable to incorporate them into protected area monitoring activities.

\section{Introduction}

Monitoring biodiversity in protected areas (PAs) forms an integral component of assessing their performance and providing the necessary information for effective management. Invertebrates constitute a significant proportion of terrestrial and freshwater biodiversity (Mound \& Gaston 1993), serve a series of critical ecosystem functions (Losey \& Vaughn 2006), and as a consequence must necessarily be considered in PA monitoring systems (Vane-Wright 1993; Woodroffe \& Ginsberg 1998). However, monitoring with invertebrates is associated with a series of regularly cited and well-recognised challenges (Dobson 2005; Lovell et al. 2010). These include their enormous richness and diversity of habits and habitats, inadequate systematic and biological knowledge for many groups, and the associated shortage of expertise and capacity (Mound \& Gaston 1993). Nonetheless, the field of insect bioindication and monitoring has developed substantially over the past two to three decades. A range of solutions, as well as several highly successful case studies of the use and incorporation of invertebrates in monitoring, now exist. As a consequence, the advantages of their inclusion have started to outweigh perceived and real disadvantages.

Monitoring has a long history in entomology with long-term data series being used, for example, to develop forecasting systems in pest management (Conrad, Fox \& Woiwod 2007). The Rothamsted Insect Survey (UK) has, for example, been monitoring the relative abundance of insects since the 1960s (Woiwod \& Harrington 1994). Indeed, butterfly monitoring in the UK is amongst the most comprehensive current monitoring programmes using insects. Here, four schemes provide complementary information on the distribution, abundance and diversity of butterfly assemblages. These schemes include mapping and multiscale atlases to monitor changes in species distributions, Red Data Books on species conservation status, transects that provide information on population trends and a system of occasional surveys of selected species (Thomas 2005). Together these data are extremely valuable for butterfly conservation and they provide substantial insight into annual and long-term trends in the diversity, abundance and distribution of the species concerned (Conrad et al. 2007).

Significant advances have also been made in South Africa, and elsewhere, over the last three decades (McGeoch 2002), both with regard to improvements in invertebrate systematics (Speight \& Castella 2001; Telford \& Littlewood 2008) and development of invertebrate bioindicators and their use in monitoring (McGeoch 2007; Samways, McGeoch \& New 2010). In this article, we 
Dates:

Received: 05 May 2010 Accepted: 27 Jan. 2011 Published: 13 May 2011

How to cite this article: McGeoch, M.A., Sithole, H., Samways, M.J., Simaika, J.P., Pryke, J.S., Picker, M., et al., 2011, 'Conservation and monitoring of invertebrates in terrestrial protected areas', Koedoe 53(2), Art. \#1000,

13 pages. doi:10.4102/ koedoe.v53i2.1000
(C) 2011. The Authors. Licensee: OpenJournals Publishing. This work is licensed under the Creative Commons Attribution License. use a selection of taxa and case studies (which is by no means comprehensive) to demonstrate the value and feasibility of both monitoring invertebrates in PAs and including them in broader conservation assessments and biodiversity monitoring programmes. We discuss the objectives, opportunities and constraints specific to invertebrate monitoring in PAs, with a particular focus on South Africa. We identify suitable taxa for monitoring based on a range of monitoring objectives and experiences, and make recommendations for the implementation of an invertebrate monitoring programme for PAs in South Africa.

\section{Why monitor invertebrates in protected areas?}

One of the key reasons for conserving and monitoring invertebrates in their own right (i.e. as the subject of monitoring), particularly in PAs, is to ensure the adequate protection of rare and threatened invertebrate species and communities (Samways 1993a). Nonetheless, invertebrates are also useful, appropriate and often highly effective and informative indicators of other elements of biodiversity, ecosystem function and restoration, system health and associated threats, including invasive alien species (McGeoch 2007). As discussed later, invertebrates provide sensitive, appropriate and logistically feasible target taxa for monitoring a wide cross section of PA management objectives (Table 1).

In November 1995, South Africa ratified the Convention on Biological Diversity (CBD) under which signatories are obligated to develop a strategic plan for the conservation and sustainable use of biodiversity. Meeting the goals of the Convention requires intensive national effort including (1) discovery, description and inventory of species, (2) analysis and synthesis of information into predictive classification systems, and (3) organisation of this information into an efficiently retrievable form that best meets the needs of science, conservation and society. Invertebrates necessarily form a significant component of this task as they not only perform critical roles in ecosystems (via pollination, decomposition, soil property maintenance, predation, parasitism, and herbivory; see for example, Lawrence (1953), Scholtz and Holm (1985) and Scholes and Walker (1993)) but also contribute disproportionately to biodiversity and outnumber plant and vertebrate richness several fold (Grimaldi \& Engel 2005; Samways 2005).

Although lesser known than in the case of vertebrates and plants, several South African invertebrate taxa also display high levels of endemism. Many invertebrates have narrow ranges; for example, in KwaZulu-Natal alone seven species of butterfly, about 80 species of snail, and more than 200 species of millipede are found exclusively in the province (Pringle, Henning \& Ball 1994; Hamer 1998; Herbert \& Kilburn 2004). These species require conservation action to ensure their survival because of their small distribution ranges and increasing rates of land transformation (Thompson 2008). Another example is the very high concentration of taxa with a southern Gondwanan ancestry that are restricted to the Cape Fold mountains. This very rich South African Gondwanan fauna (800 species, 200 families) has its primary hotspot on the Cape Peninsula (a substantial proportion of which constitutes Table Mountain National Park [TMNP] in the Western Cape [Day 2005]). High levels of endemism (111 Cape Peninsula endemics, according to Picker and Samways [1996]) are concentrated in refugial habitats such as mountain streams, southern Afrotemperate forest and caves. The Cape Floristic Region, in general, has a distinctive invertebrate fauna, with high levels of endemism in gall-forming insects (Wright \& Samways 1998), leafhoppers (Stiller 2002), dung beetles (Davis 2002), scorpions (Prendini 2005), millipedes (Hamer \& Slotow 2002), velvet worms, (Onychophora) (Daniels et al. 2009; Hamer, Samways \& Ruhberg 1997), heelwalkers (Mantophasmatodea) (Damgaard et al. 2003) and lycaenid butterflies (Cottrell 1985). Other biomes are probably less well studied in terms of their invertebrate fauna and levels of endemicity, but the more northern Afrotemperate forests, and even grassland and savanna have high levels of narrow endemism for some taxa that have been investigated in this respect (e.g. Hamer, Slotow \& Lovell 2006; Hamer \& Slotow 2009).

PAs play a vital role in the conservation of such narrow range endemics, and these species are generally considered 'species of special concern' in PA management objectives (Table 1). For example, in the TMNP several invertebrates require special attention, such as Colophon westwoodi (Coleoptera: Lucanidae) and Trimenia malagrida malagrida (Lepidoptera: Lycaenidae). Peripatopsis alba is an endangered cave-dwelling velvet worm confined to Table Mountain (Hamer et al. 1997). These taxa have been found only at very few localities and these sites thus require special conservation management. 
TABLE 1: Examples of biodiversity objectives in protected areas (see McGeoch, M.A., Dopolo, M., Novellie, P., Hendriks, H., Freitag, S., Ferreira, S., et al., 2011, 'A strategic framework for biodiversity monitoring in SANParks', Koedoe 53(2), Art. \#991, 10 pages. doi:10.4102/koedoe.v53i2.991) and relevant associated invertebrate monitoring.

Protected area objective: Status and trend monitoring

Species of special conservation concern $\quad$ Circellium bacchus M.S., 2007, 'What have Red Lists done for us? The values and limitations
M. of protected species listing for invertebrates', in A.J. Stewart, T.R. New \& doi:10.1079/9781845932541.0076)

Callioratis millari

(Entumeni Nature Reserve)

Orachrysops niobe Brenton Blue

(Brenton Blue Butterfly Reserve)

Peripatopsis alba

(caves in Table Mountain National Park)

River Health Programme
(includes macroinvertebrate

Freshwater systems

(Revenga, C., Campbell, I., Abell, R., De Villiers, P. \& Bryer, M., 2005, 'Prospects (includes macroinvertebrates and is for monitoring freshwater ecosystems towards the 2010 targets', Philosophical (inducted in several PAs) Transactions of the Royal Society of London B 360, 397-413. doi:10.1098/ rstb.2004.1595, PMid:15814353, PMCid:1569454)

-

Alien and invasive species

Dragonfly Biotic Index

Thermal tolerances and climate change

Linepithema humile, Argentine ant

(Jonkershoek Nature Reserve)

Snails

(West Coast and Kruger National Parks)

Resource use

Imbrasia belina, Mopane worm (Kruger National Park)

Gonometa species, African wild silk moths (Kgalagadi Transfrontier Park)

Habitat representation and persistence Ants

(Hanski, I. \& Pöyry, J., 2007, 'Insect populations in fragmented habitats', in A.J. (Kruger National Park; Pilansberg Game Reserve) Stewart, T.R. New \& O.T. Lewis (eds.), Insect conservation biology, pp. 175-202, CABI, Wallingford. doi:10.1079/9781845932541.0175)

Dung beetles

(Tembe Elephant Park)

Alluvial diamond mining

Disease

Disease vectors

(malaria, ectoparasites)

Climate and climate change

(Wilson, R.J., Davies, Z.G. \& Thomas, C.D., 2007, 'Insects and climate change: Processes, patterns and implications for climate change', in A.J. Stewart, T.R. New \& O.T. Lewis OT (eds.), Insect conservation biology, pp. 245-279, CABI, Wallingford.)

Ants

(Greater Cederberg Biodiversity Corridor)

Springtails

(Prince Edward Islands Special Nature Reserve)

Reference

Chown, S.L., Scholtz, C.H., Klok, C.J, Joubert, F.J. \& Coles, K.S., 1995, 'Ecophysiology, range contraction and survival of a geographically restricted African dung beetle (Coleoptera, Scarabaeidae)', Functional Ecology 9, 30-39. doi:10.2307/2390087

Armstrong, A.J. \& Louw, S., 2010, 'KZN Biodiversity Status Assessment Report: Millar's tiger moth, Callioratis millari', Ezemvelo KZN Wildlife Report, Pietermaritzburg. http://www. brentonblue.org.za/

Sharratt, N.J., Picker, M.D. \& Samways, M.J., 2000, 'The invertebrate fauna of the sandstone caves of the Cape Peninsula (South Africa): Patterns of endemism and conservation priorities', Biodiversity and Conservation 9, 107-143. doi:10.1023/A:1008968518058

Dallas, H.F., 2007, 'The influence of biotope availability on macroinvertebrate assemblages in South African rivers: implications for aquatic bioassessment', Freshwater Biology 52, 370-380. doi:10.1111/j.13652427.2006.01684.x

See text

See text

De Kock, A.E. \& Giliomee, J.H., 1989, 'A survey of the Argentine ant, Iridomyrmex humilis (Mayr), (Hymenoptera: Formicidae) in South African Fynbos', Journal of the Entomological Society of Southern Africa $52,157-164$

Odendaal, L.J., Haupt, T.M. \& Griffiths, C.H., 2008, 'The alien invasive land snail Theba pisana in the West Coast National park: Is there cause for concern?', Koedoe 50, 93-98.

De Kock, K.N. \&. Wolmarans, C.T., 2008, 'Invasive alien freshwater snail species in the Kruger National Park, South Africa', Koedoe 50, 49-53.

McGeoch, M.A., 2002, 'Insect conservation in South Africa: An overview', African Entomology 10, 1-10.

Veldtman, R., McGeoch, M.A. \& Scholtz, C.H., 2002, 'Variability in cocoon size in southern African wild silk moths: Implications for sustainable harvesting', African Entomology 10, 127-136.

Sithole, H., Smit, I.P.J. \& Parr, C.L., 2010, 'Preliminary investigations into a potential ant invader in Kruger National Park, South Africa', African Journal of Ecology 48, 736-743.

Parr, C.L., Bond, W.J. \& Robertson, H.G., 2002, 'A preliminary study of the effect of fire on ants (Formicidae) in a South African savanna', African Entomology 10, 101-111.

Botes, A., McGeoch, M.A. \& Van Rensburg, B.J., 2006a, 'Elephant- and human-induced changes to dung beetle (Coleoptera: Scarabaeidae) assemblages in the Maputaland Centre of Endemism', Biological Conservation 130, 573-583. doi:10.1016/j.biocon.2006.01.020

Lyons, C., Picker, M.D. \& Carrick, P., 2008, 'Evaluating restoration success of alluvial diamond-mined sites using invertebrate community indicators', Mine Closure Proceedings 3, 821-830.

Braack, L. \& Kryger, P., 2003, 'Insects and savannah heterogeneity', in J.T. du Toit, K.H. Rogers \& H.C. Biggs (eds.), The Kruger experience, pp. 263-275, Island Press, London.

Dallas, H.F., 2008, 'Water temperature and riverine ecosystems: An overview of knowledge and approaches for assessing biotic responses, with special reference to South Africa', Water SA 34, 393-404.

Botes, A., McGeoch, M.A., Robertson, H.G., Van Niekerk, A., Davids, H.P. \& Chown, S.L., 2006b, 'Ants, altitude and change in the northern Cape Floristic Region', Journal of Biogeography 33, 71-90. doi:10.1111/j.13652699.2005.01336.x

McGeoch, M.A., Le Roux, P.C., Hugo, A.E. \& Chown, S.L., 2006, 'Species and community responses to short-term climate manipulation: Microarthropods in the subAntarctic', Austral Ecology 31, 719-731. doi:10.1111/ j.1442-9993.2006.01614.x 


\section{Tackling the knowledge challenge}

The conservation and monitoring of invertebrates, including those in PAs in South Africa, are well-known to present unique taxonomic challenges given their overwhelming diversity (Vane-Wright 1993; Grimaldi \& Engel 2005; Scholtz \& Chown 1995). With the comparative exception of butterflies, dragonflies, trapdoor and baboon spiders (Dippenaar-Schoeman 2002; Henning \& Henning 1989; eds. Henning, Terblanche \& Ball 2009; Samways 2006), the conservation status of most invertebrate groups in South Africa is poorly known (other comparatively well-known groups include terrestrial molluscs, one genus of millipede, and Onychophora) (Scholtz \& Chown 1995). For example, a systematic conservation planning project, initiated by the Gauteng Department of Agriculture, Conservation and Environment (DACEL) in 2000, aimed to include broad representation of threatened species from a range of taxonomic groups (DACEL 2003). However, inclusion of the invertebrates proved a particular challenge owing to the lack of available information for identifying species of conservation concern. As a result, an expert consultation approach was followed to identify candidate species for inclusion. Through this process, insect and arachnid species were identified and included in the first version of the conservation plan (DACEL 2003). Surveys were then conducted for several of these species to obtain additional distribution data. However, as a result of these surveys several species were removed from the expert list when they were found to be far more widespread than originally thought.

This example well illustrates the challenges involved in identifying invertebrate species of conservation concern and deciding which need to be monitored. Expert opinion in itself may be insufficient and available distribution data are often inadequate. Therefore, whilst surveying and quantifying invertebrate biodiversity are valuable in their own right (Lovell et al. 2010), a focus on better-known groups is likely to be more effective for the purposes of conservation planning and monitoring in PAs. At present, management decisions are often based on information on the distribution of vertebrates or plants, with the assumption that the latter will also benefit invertebrates. However, whilst there often is a broad relationship between plant and insect diversity at large spatial scales (e.g. Procheş et al. 2009), this approach is insufficient to guarantee the conservation of rare invertebrate species at the finer spatial scales at which conservation action usually occurs (e.g. Lovell et al. 2007; Panzer \& Schwartz 1998).

\section{Advances}

Despite the rather dismal reflection of the status of invertebrate knowledge as described above, knowledge of selected invertebrate taxa in South Africa is increasing exponentially. Monitoring efforts in some instances are also supported by adequate keys, distribution information and baseline conservation status assessments. For example, the South African Butterfly Conservation Atlas (SABCA) project, launched in 2007 to determine the distribution and conservation status of butterflies in South Africa, Lesotho and Swaziland (http:/ / sabca.adu.org.za/), will be published in 2011. It will incorporate field data (2007-2010) and museum and private collection records (eds. Henning et al. 2009). The Lepidopterists' Society of Southern Africa has been instrumental in these activities and their achievements provide an excellent example of the role of citizen scientists along with semiprofessional and professional entomologists in promoting invertebrate conservation and improving the knowledge base with regard to particular taxa.

As a charismatic group of taxa, butterflies have long received the attention of entomologists, collectors and conservationists across the world. Similar approaches and activities for other invertebrate groups are nonetheless possible. For example, South Africa has a rich arachnid fauna with about 5000 known species, representing $6 \%$ of global arachnid diversity. Although they constitute a diverse and ecologically important group of invertebrates in South Africa, they have traditionally been comparatively poorly sampled in some areas. However, in 1997 the South African National Survey of Arachnida (SANSA) was initiated by the Biosystematics Unit (ARC-Plant Protection Research Institute). SANSA aims to inventory the arachnofauna of the country and forms part of the Threatened Species Programme of the South African National Biodiversity Institute (SANBI) to determine the distribution and conservation status of spiders and scorpions.

One of the focus areas of SANSA is to survey PAs to obtain species-specific information, compile inventories and to determine which species in South Africa receive some protection. More than 86 surveys in PAs are currently underway, of which 25 have already resulted in published annotated checklists that provide information on abundance, behaviour and the distribution of arachnid species. Several forms of participation have involved PAs, including SANSA surveys, surveys by PA managers and rangers, student research projects (seven MSc projects completed), by-catch data from other research projects and records submitted by the public. This has dramatically increased the knowledge of the spider fauna of PAs and with material made available to taxonomists has resulted in the description of several new species (e.g. Wesolowska \& Haddad 2009). During this survey a record 430 species were recorded, which represent more than $20 \%$ of the South African spiders and include several new and undescribed species (Haddad, DippenaarSchoeman \& Wesolowska 2006; Wesolowska \& Haddad 2009). Long-term surveys in PAs also increase the number of species sampled. For example, during the survey of the Kruger National Park (KNP) 152 species were reported in 2003, increasing the number currently listed for the park to 305 (Dippenaar-Schoeman \& Leroy 2003, see also DippenaarSchoeman 1988, 2006). PAs have proven to be particularly valuable sites to SANSA, both from the perspective of encountering pristine habitat and high diversity, as well as for the safety of survey teams (Dippenaar-Schoeman et al. 1999, 2005). 


\section{Species inventories for protected areas}

Species inventories are critical for effective PA management and are generally considered to be important by PA managers, specialist taxon scientists, citizen scientists and the layperson alike. Such inventories form the basis of identifying the presence of species of special conservation concern in PAs (Table 1), are valuable in regional conservation planning processes, and are the first step in any monitoring programme across a range of monitoring objectives (Rohr, Kim \& Mahan 2007). Species inventories, when repeated over time, may also be used as a tool to monitor the loss or gain of species in PAs (Droege, Cyr \& Larivée 1998).

Because of the importance of inventories in species conservation assessment and PA management, Engelbrecht (2010) investigated to what extent and how invertebrate species inventories are currently applied in PA management in South Africa. PA managers and ecologists were asked, using a questionnaire-based survey, to comment on whether (1) a documented management plan existed for the PA in question, (2) any invertebrate species inventories existed for the PA, and if so, (3) whether those inventories had been used to guide the development of any of the management goals or actions for the PA. Although the overwhelming majority considered inventories desirable, very few of the responses received indicated that invertebrates were specifically considered in management goals or actions. Those that did included the Brenton Blue Butterfly Reserve (Western Cape) and the Suikerbosrand Nature Reserve (Gauteng), which is home to the Heidelberg Copper (Engelbrecht 2010). In other cases, the principal value of inventories was to tourists and scientists visiting the PA. The outcome of this study illustrates that although insect conservation and monitoring have not yet become mainstream in PA planning and management processes, the potential value of inventories is (1) widely acknowledged and (2) would be more suited to this purpose where accompanied by information on richness patterns, distributions, and rare and indicator species (Engelbrecht 2010).

\section{Use of invertebrates in conservation planning}

Invertebrates have been successfully used in systematic conservation planning in South Africa. For example, in KwaZulu-Natal, a range of spatial products that include invertebrates (e.g. databases of distribution records, geographical information system layers and predicted distribution maps) have been developed to support the assessment of land use change applications by the Integrated Environmental Management (IEM) team of Ezemvelo KZN Wildlife (see also an example by Edge (2005) on butterflies in the southern Cape). These products include the Ezemvelo KZN Wildlife Biodiversity Database, which, as of July 2009, contains distribution records for 3649 invertebrate species and subspecies, both within and outside of PAs. These records are used in species distribution modelling and to indicate which species occur, or are likely to occur, on land subject to applications for land use change. To date, only
Red Listed species and those endemic to the province have been included in this modelling. The first spatial product incorporating modelled invertebrate distributions included 98 invertebrate species and subspecies (Armstrong 2002; Goodman 2000).

As shown in Table 2, despite this and other available and related tools in KwaZulu-Natal, invertebrates have been explicitly included in only a small proportion of land use change applications under the National Environmental Management Act (NEMA) (Act 107 of 1998), where the proposed land use change may have significant impacts on species of special concern. Various mitigation measures were proposed by Ezemvelo KZN Wildlife as befitting the range of invertebrate taxa concerned. The recommendations ranged from no mitigation specific to invertebrates, through restriction of the proposed land use to certain portions of the land (e.g. to already transformed portions of the land), to setasides for invertebrate conservation. In one case, refusal of the permit was recommended on invertebrate conservation grounds. Some of these recommendations were incorporated into the Record of Decision issued by the provincial Department of Agriculture and Environmental Affairs (now the Department of Agriculture, Environmental Affairs and Rural Development), whilst others were not.

One of the insights gained from the aforementioned process is the need to strengthen the profile of invertebrates in conservation planning, both within and outside of PAs, so that charismatic umbrella vertebrate taxa are not relied upon to effect the conservation of invertebrates and their habitats. The Ezemvelo KZN Wildlife IEM team now communicates to all relevant parties when umbrella species are used for invertebrate conservation purposes. The need to conserve invertebrates is not readily accepted or appreciated by some permitting authorities, applicants and environmental consultants, and some lack expertise on invertebrates and therefore ignore them. Profiling of invertebrates and training of consultants are required to successfully integrate invertebrate conservation into processes legislated by NEMA and its subsidiary Acts. This will allow invertebrates to be considered explicitly and conserved in areas subject to change in land use.

\section{Threats to invertebrate diversity in protected areas}

Invertebrates are susceptible to the same key threats as other biodiversity elements, namely habitat loss and degradation, invasive alien species and climate change (McGeoch 2002; New 1995; Scholtz \& Chown 1993). A recent assessment of invertebrate diversity in the TMNP provides a good example of threats to invertebrates (Pryke \& Samways 2008, 2010). As is the case elsewhere in the Fynbos Biome, most of the upper elevational areas of the TMNP are well protected, whereas the low-lying areas are of significant concern. For example, the importance of conserving lowlands is well illustrated by Noordhoek wetlands (a new addition to TMNP), with two new water beetle species recently identified from the area 
TABLE 2: The number of land use change applications in KwaZulu-Natal with species concerns, and the number of these with invertebrate concerns as ascertained by Ezemvelo KZN Wildlife, the mitigations proposed, and the final decisions by the competent authority.

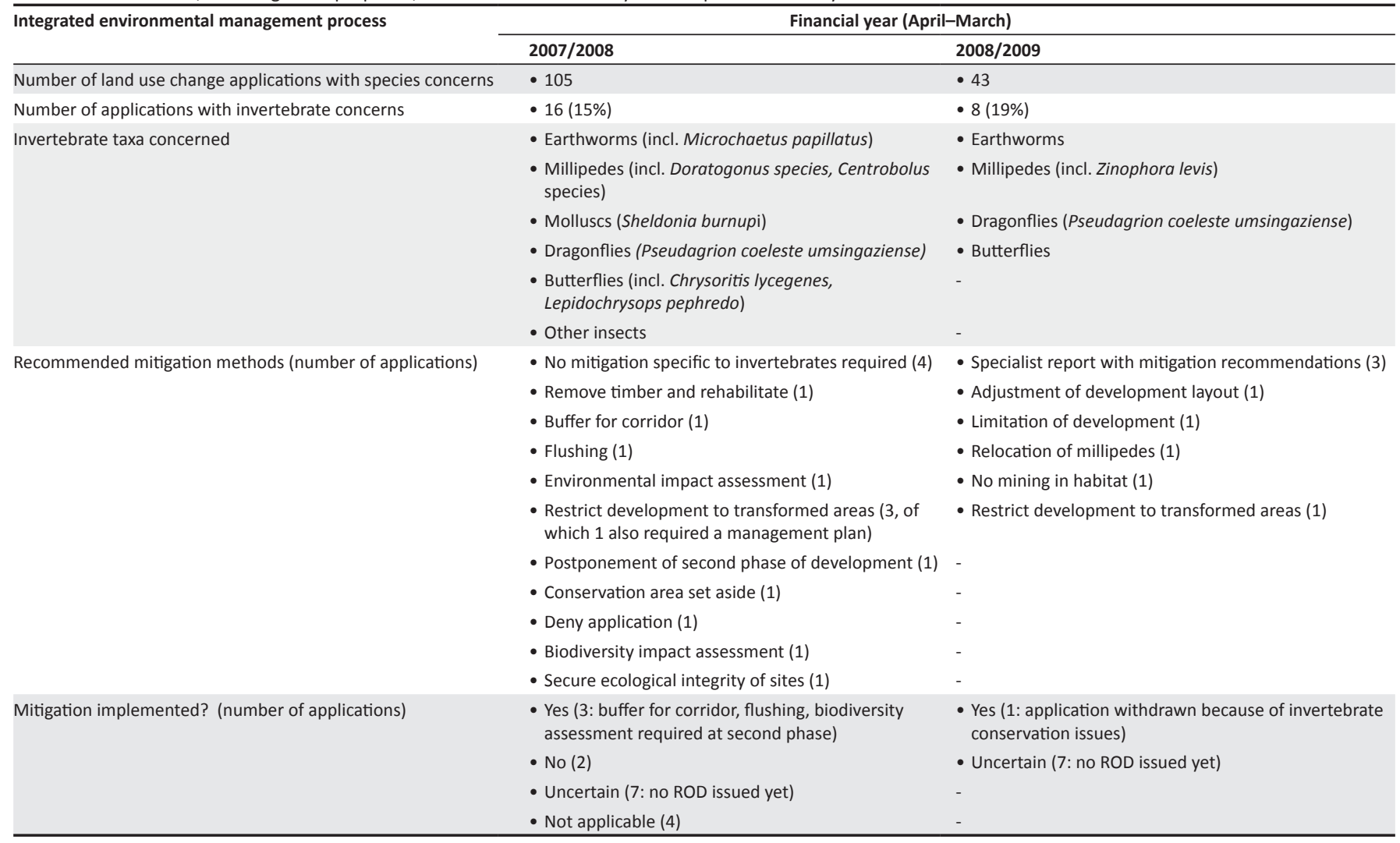

Note: Numbers in brackets indicate the number of applications, unless otherwise indicated. ROD, record of decision.

(closest known localities were Zaire and Mozambique), and a third species new to science (Pryke \& Samways 2009a). Lower-lying areas that are covered by plantations tend to have lower invertebrate species richness, and for some species lower abundance, compared to natural forests and fynbos (Pryke \& Samways 2009b). Invertebrate assemblages of indigenous natural forests are likely to be more difficult to restore than those of fynbos and thus the protection of the remaining natural forests in the TMNP is a conservation priority (Pryke \& Samways 2009b).

Monitoring invertebrate responses to fire (e.g. frequency and intensity) is also important in PAs within biomes where fire is a key habitat management tool, such as savanna and fynbos (Parr et al. 2002). Fire is a particular conservation risk in Mediterranean-type biomes and, although it is an essential element in the maintenance of biodiversity, fire regimens (frequency, intensity and timing) have been significantly altered by increasing human population densities, resulting in too frequent, too infrequent and other ecologically undesirable fire properties (Forsyth \& Van Wilgen 2008). A study by Pryke (2008) showed that the invertebrates in the TMNP demonstrated differential short-term resilience to fire, especially with regard to species richness and abundance. Some components of the invertebrate assemblage were remarkably resilient to fire (particularly ants), whilst others were far more conservative (pollinators and detritivores). Invertebrates were also found to recolonise high-altitude grasslands in the Drakensberg within a short space of time after burning (Uys, Hamer \& Slotow 2006). However, although not well studied, fire in Afrotemperate forest may have a negative impact on some less mobile taxa such as molluscs (Uys, Hamer \& Slotow 2010). In terms of firerelated monitoring objectives in PAs, invertebrates are thus an important element of monitoring the status of and trends in habitat persistence, degradation and rehabilitation (Table 1).

\section{Invasive invertebrates}

Monitoring programmes for invertebrate conservation in PAs should also consider invasive invertebrates (Table 1). Established invaders may thrive and come to dominate local communities, often causing a loss of biodiversity and impacting on ecosystem functioning (Vilà et al. 2010). Whilst a few terrestrial alien invasive invertebrates are well known in South Africa (e.g. the Argentine ant (Linepithema humile) and the European wasp (Vespula germanica)), the majority remain inconspicuous in local faunas owing to a lack of thorough taxonomic surveys. In the absence of precise taxonomic identification by experts, the number of alien species is often greatly underestimated. Alien invertebrates in South African PAs span most of the higher-level taxa and include earthworms, slugs, snails, millipedes, woodlice, spiders, mites and insects such as earwigs, wasps and ants (Macdonald et al. 2003; Raharinjanahary 2007). Whilst some of these alien species have not become invasive, many invaders have the potential to impact native ecosystems, either directly through predation or indirectly by disrupting mutualisms or through interference competition (Kenis et 
al. 2009). For example, many alien earthworms are highly invasive and often dominate faunas even in relatively untransformed habitats (e.g. Horn, Plisko \& Hamer 2007). Most biological invasions arise through human-mediated extra-range dispersal pathways (Wilson et al. 2009) and can also include range extensions of native species, such as the Cape honeybee (Apis mellifera capensis) (Braack \& Kryger 2003; Valéry et al. 2008).

Monitoring or research programmes that include accurate taxonomic identifications are the most likely way of detecting new alien species and structured monitoring programmes for target species allow for early detection and potentially rapid control. Those involved in invertebrate monitoring should not only be familiar with known invasives, but be on the lookout (early detection) for species that are problematic in other countries, but have not yet been recorded in South Africa. Examples include the yellow crazy ant (Anoplolepis gracilipes) and red imported fire ant (Solenopsis invicta) (Lowe et al. 2000).

\section{What to monitor? Selection of invertebrate taxa and habitats}

The debate on which taxa are best suited for inclusion in monitoring programmes is long running and closely related to the debate on which taxa are good bioindicators of environmental change, or of broader biodiversity per se (Kremen et al. 1993; McGeoch 1998). More than 32 criteria have been identified for guiding the choice of taxa suitable for bioindication and monitoring (McGeoch 1998). The relative importance of these particular criteria is determined principally by the monitoring objective. Biodiversity monitoring in PAs encompasses several broad objectives and invertebrates are potentially both relevant and useful for most of these (Table 1). However, all taxa have a range of advantages and disadvantages as monitoring tools and these should be evaluated to assess their suitability in a particular monitoring context (Samways 1993b).

Decisions on what to monitor must also necessarily consider the focal taxa and habitats along with logistic feasibility of the proposed exercise. Different invertebrate taxa are obviously more, or less, appropriate for monitoring in particular environments and are differentially sensitive to particular stressors. Table 3 provides an assessment of the value of selected higher-level taxa to monitoring based on a range of key generic criteria. The outcome of this assessment provides guidance for selecting which higher taxa to focus on a priori, before proceeding with more specific indicator testing as would be required to achieve more specific monitoring objectives (see McGeoch [1998] and McGeoch, Van Rensburg \& Botes [2002] for general approach). We selected 16 objectives and criteria that are most relevant in a PA context and assessed a range of higher taxa against these. Rather than assessing all higher taxa, a subgroup of seven, which were considered to be those broadly most feasible in a South African context (based on the collected specialist opinion and experience of the authors), was selected a priori. Other taxa may well be relevant and suitable for more narrowly defined purposes. The taxa were scored for each criterion (see explanation in Table 3) and ranked according to a descending score (left to right, Table 3). Odonata, Formicidae, Lepidoptera (butterflies) and Scarabaeidae were considered best suited for monitoring in PAs. Interestingly, Coleoptera, Hymenoptera and Lepidoptera (along with molluscs and arachnids) currently receive most research attention in South African National Parks (Figure 1). For example, dung beetles, whilst potentially useful indicators as a result of their specialised distribution patterns, require fine-scale spatial data to realise this potential (Davis 2002). Given the rapid increase in knowledge and expertise on South Africa's arachnid fauna, particularly in PAs, the score for this taxon is likely to increase in the foreseeable future. We consequently use the Odonata and Formicidae (Hymenoptera) as two of the highest-scoring taxa in our assessment to illustrate aspects of the suitability and application of invertebrates for monitoring in PAs.

\section{Odonata}

Several freshwater monitoring schemes involving macroinvertebrates are well developed with a long history, for example the River Invertebrate Prediction Classification System used in the UK to monitor the pollution status of water courses (Wright et al. 2000) and the South African Scoring System (SASS) (Revenga et al. 2005). Good taxonomic and biological information, along with knowledge of species conservation status and responses to habitat quality are amongst the key suitability criteria in invertebrate monitoring (Table 3). The Odonata in South Africa perhaps best exemplify this with existing Red Data information and comprehensive field guides that make working with the group broadly accessible to biologists, the public and citizen scientists (Samways 2006, 2008). South Africa's freshwater systems are under intense pressure ( $\mathrm{Nel}$ et al. 2007) and the Odonata are sensitive indicators of the quality of these systems. This includes their response to pollution and invasive alien species impacts (Chovanec 2000), as well as their recovery after alien plant removal in rivers in PAs in South Africa (Samways \& Sharratt 2010).

In addition to the well-known and widely used SASS system (Dallas \& Day 1993; Revenga et al. 2005), the Dragonfly Biotic Index (DBI) provides a measure of ecological integrity for freshwater systems. The DBI is a weighted index (see Table 4) based on the quantitative assessment of three subindices of species distribution, threat status and sensitivity to disturbance (Simaika \& Samways 2008, 2009a). The total DBI of a water body (stream, river or pool) reflects the total odonate assemblage, thus allowing for water bodies to be compared and restoration success to be monitored (Simaika \& Samways 2008). Every South African odonate species has been assigned a score (Samways 2008). The DBI has been tested and applied in biomonitoring (Simaika \& Samways 2009a), 2011 to measure habitat recovery (Simaika \& Samways 2008) and select sites for conservation (Simaika \& Samways 2009b). Previous work has shown a strong correlation 
TABLE 3: An assessment of the suitability of taxonomic groups to be used for monitoring in protected areas, according to a range of objectives (see Table 1) and general suitability criteria.

\begin{tabular}{|c|c|c|c|c|c|c|c|}
\hline \multirow[t]{2}{*}{ Suitability criteria } & \multicolumn{7}{|c|}{ Taxa } \\
\hline & Odonata & $\begin{array}{c}\text { Hymenoptera } \\
\text { (Formicidae) }\end{array}$ & $\begin{array}{l}\text { Lepidoptera } \\
\text { (butterflies) }\end{array}$ & $\begin{array}{c}\text { Coleoptera } \\
\text { (Scarabaeidae) }\end{array}$ & $\begin{array}{l}\text { Araneae } \\
\text { (spiders) }\end{array}$ & Isoptera & Orthoptera \\
\hline \multicolumn{8}{|l|}{ Relevance to objective } \\
\hline Biodiversity ${ }^{b}$ & Yes & Yes & Yes & Yes & Yes & No & No \\
\hline Function $^{c}$ & No† & Yes & Yes & Yes & No† & Yes & No $†$ \\
\hline Threat & Yes & Yes & Yes & Some cases & Some cases & No & No \\
\hline Scale of relevance ${ }^{d}$ & National & National & National & Biome & National & Biome & Biome \\
\hline Existence of Red List ${ }^{\mathrm{e}}$ & Yes & No & Yes & No & No & No & No \\
\hline Systematic knowledge $\mathrm{f}^{f}$ & High & Medium & High & High & Medium & High & Medium \\
\hline Available expertise ${ }^{g}$ & High & High & High & High & Medium-high & Low & Low \\
\hline Potential for collaborative involvement ${ }^{\mathrm{h}}$ & High & High & High & High & Medium & Low & Low \\
\hline Available sampling and monitoring methodology' & High & High & High & High & Low & Low & Low \\
\hline Practicality ${ }^{j}$ & High & Medium & Medium & Medium & Medium & Low & Medium \\
\hline Used in monitoring globally & Medium & High & High & High & Medium & Low & Low-medium \\
\hline Trophic level diversity' & 1 & 2 & 1 & 1 & 1 & 2 & 1 \\
\hline Published keys $^{m}$ & High & High & High & Medium & Medium & Medium & Low \\
\hline Published supporting info for $\mathrm{SA}^{\mathrm{n}}$ & High & High & Medium & High & Medium & Low & Low \\
\hline Final ranking $^{\circ}$ & $31[1]$ & $30.5[2]$ & $30.5[2]$ & $29.5[3]$ & $22[4]$ & $16[5]$ & $12.5[6]$ \\
\hline
\end{tabular}

Number in square brackets is the rank order of suitability of each taxon.

a, these are species that are found in protected areas and are on the IUCN Red List, endemic or of specific functional, cultural or socio-economic significance.

b, concerns the use of communities or assemblages to monitor the status of and trends in biodiversity.

c, refers to the ecosystem services that taxa of a concerned group perform, for example, pollination, decomposition and nutrient cycling.

d, refers to whether the taxa in the group are appropriate for monitoring across all protected areas or only in specific biomes.

e, refers to whether Red Data Book or List for the group exists following the IUCN Red List criteria.

f, refers to the status of published systematic knowledge of taxa in a particular group.

g, refers to number of experts (and their accessibility) available (nationally and internationally) to provide taxonomic support.

${ }^{h}$, refers to existing or potential PA collaboration with other institutions or experts on concerned taxa; it is based on number of researchers studying the group (in South Africa) and their collaboration with protected area agencies.

', refers to whether sampling and monitoring methods have been published and have been used frequently in monitoring concerned taxa in group.

, refers to the ability to sample and process samples quickly, effectively, inexpensively and by non-specialists.

$k$, refers to availability of data on taxa for PAs that could provide general baseline information for future monitoring.

refers to number of trophic levels in the taxon.

, refers to published keys that can be used to identify taxa of a concerned group.

refers to relevant published results for South African ecosystems.

, each criterion was given a score (scores then summed) as follows: $\mathrm{No}=0$, Yes $=1$, some cases $=0.5 ;$ national or biome $=1 ;$ high $=3 ;$ medium-high $=2.5$, medium $=2$, low-medium $=1.5$, low $=$

$\dagger$, although these taxa serve important predatory and herbivory functions, their significance has been less directly linked to ecosystem services than the other taxa considered.

$\$$, with the widespread adoption of a set of survey methods by SANSA and their work in PAs (see text), these scores may increase.
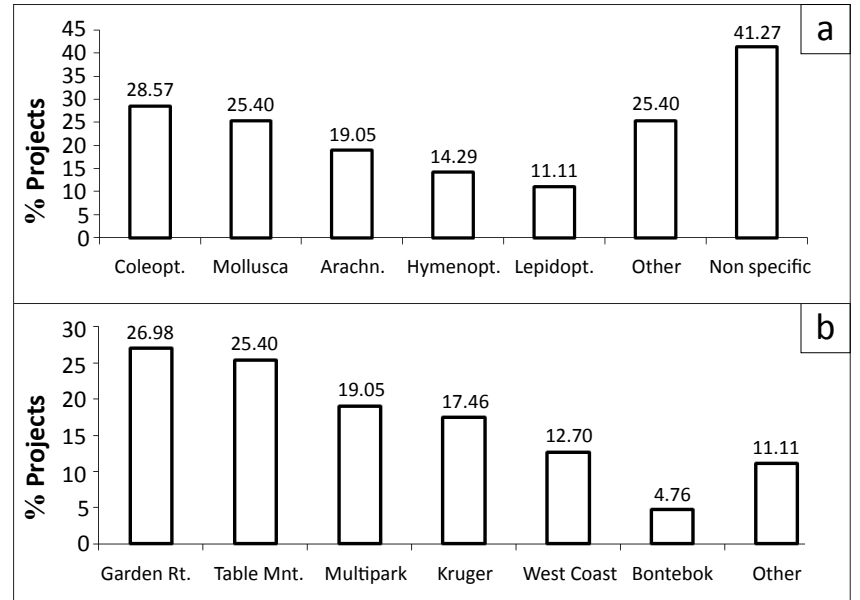

Arachn., Arachnida; Coleopt., Coleoptera; Lepidopt., Lepidoptera; Hymenopt., Hymenoptera; Garden Rt., Garden Route National Park; Table Mnt., Table Mountain National Park.

FIGURE 1: Percentage of research projects $(n=63$ ) on invertebrates (a) per taxon and (b) per park (including nontaxon specific projects) currently registered with South African National Parks (as at November 2009).

between adult dragonfly scores and macroinvertebrate scores (Simaika \& Samways 2011; Smith, Samways \& Taylor 2007). An advantage of the DBI over conventional macroinvertebrate indices is that it operates at the species level and is therefore highly sensitive to habitat condition. It, therefore, has good potential for environmental assessment and monitoring freshwater biodiversity and quality, alongside SASS (Simaika \& Samways 2011). The low field effort required to obtain a DBI score for a site also makes this a low-cost and readily applied method. Odonata are therefore particularly useful for monitoring freshwater quality and landscape physiognomy around riverine and other aquatic habitats in South Africa's PAs (Samways 1993b).

\section{Formicidae}

Other important criteria to consider when selecting a taxon for monitoring include the taxonomic richness of the group, their ubiquitousness, the diversity of habitats that they occupy, their importance in ecosystem functioning and the range of functional roles that they perform in the environment (Table 3). Ant assemblages have been widely tested in the assessment of environmental disturbance and ecosystem condition and their abundances and distributions are strongly correlated with temperature and vegetation communities (Andersen \& Majer 2004; Botes et al. 2006b; Kaspari \& Majer 2000; Underwood \& Fisher 2006). However, equally important is the cost, effort and capacity associated 
TABLE 4: The subindices of the Dragonfly Biotic Index (DBI) range from 0 to 3 . The DBI is based on three subindices relating to geographical distribution, level of threat, and sensitivity to habitat change, with particular reference to invasive alien riparian trees. The DBI is the sum of the scores for the three subindices, and ranges from 0 to 9. A common, widespread, not-threatened and highly tolerant (of disturbance) species would score $0(0+0+0)$, whilst a highly range-restricted, threatened and sensitive species would score $9(3+3+3)$.

\begin{tabular}{llll}
\hline Score & & \multicolumn{2}{l}{ Subindices } \\
\cline { 2 - 4 } & Distribution & Threat & Sensitivity \\
\hline 0 & $\begin{array}{l}\text { Very common throughout South Africa and } \\
\text { southern Africa. }\end{array}$ & LC; GS & $\begin{array}{l}\text { Not sensitive; little affected by habitat disturbance and may even benefit from } \\
\text { habitat change due to alien plants; may thrive in artificial waterbodies. }\end{array}$ \\
$\begin{array}{l}\text { Localised across a wide area in South Africa, and localised } \\
\text { or common in southern Africa; or very common in 1-3 }\end{array}$ & NT GS or VU; NS & $\begin{array}{l}\text { Low sensitivity to habitat change from alien plants; may occur commonly in } \\
\text { artificial waterbodies. }\end{array}$
\end{tabular}

2 National endemic confined to 3 or more provinces; or VU; GS or CR; NS or EN; NS Medium sensitivity to habitat disturbance such as from alien plants and bank widespread in southern Africa but marginal and very disturbance; may have been recorded in artificial water bodies.

3 Endemic or near-endemic and confined to only CR; GS or EN; GS Extremely sensitive to habitat change from alien plants; only occurs in undis1 or 2 Provinces. $\quad$ turbed natural habitat.

Source: Table modified from Simaika, J.P. \& Samways, M.J., 2008, 'Valuing dragonflies as service providers', in A. Cordoba-Aguilar (ed.), Dragonflies: Model organisms for ecological and evolutionary research, pp. 109-123, Oxford University Press, Oxford

CR, critically endangered; EN, endangered; GS, global status; NS, national status.

with sampling, identifying and analysing the taxon and, for example, the feasibility of using parataxonomists for such species-rich groups (New 1998; Underwood \& Fisher 2006).

Ant monitoring in South Africa has gained significant momentum over the last decade. For example, the Iimbovane project (http:/ /academic.sun.ac.za/iimbovane) is a spatially extensive and temporarily replicated ant monitoring programme (currently focussed in the Western Cape), where equivalent information on invertebrates is rare (Driver et al. 2005; Koch et al. 2000). It thus delivers baseline data of species distributions in different vegetation types in two biodiversity hotspots (the Fynbos biome and the Succulent Karoo biome), against which the impact of future environmental change can be assessed (Braschler et al. 2010). The project uses sites that are disturbed in a variety of ways and control sites that are typically located within PAs. Spatially and temporally replicated surveys are used to detect trends and assess natural variation, including variation due to seasonality, climatic events or fire events. However, such surveys face many challenges, including securing expertise and funding for long periods. Continuity was built into the Iimbovane project by combining monitoring with a long-term outreach programme (teaching biodiversity to high school learners participating in the monitoring; see Braschler [2009]) and by involving technical staff on long-term contracts. Including both pristine and disturbed sites means that the data may be used for a variety of purposes. It is inevitable that much conservation will have to be done outside PAs, including transformed landscapes, which makes monitoring disturbed sites necessary. Control sites in PAs are particularly valuable and serve to separate various fine-scale and large-scale disturbance effects. Furthermore, where restoration is the goal for conservation, baseline data are needed on what is natural to an area and this information is often best obtained from control sites with natural vegetation such as those found inside PAs.

Faced with adopting and implementing an invertebrate monitoring programme, the KNP has also assessed the feasibility, resource requirements and cost of ant monitoring in the park. Ants were selected as one of three possible groups (the others were dung beetles and butterflies) because of the presence of taxonomic expertise in the park, a history of active collaboration with external researchers on this taxon, good baseline data on ant assemblages in the KNP being available and the ubiquitousness and relevance of the taxon in the area (Parr \& Chown 2001; Parr et al. 2004). To assess the costs associated with ant monitoring, ants were sampled from 34 plots $\left(2000 \mathrm{~m}^{2}\right.$ each) using 20 pitfall traps per plot. Traps were left open in the field for 5 days. Pitfall trapping was chosen because it is widely used for ant sampling and is considered efficient in savanna ecosystems (Parr \& Chown 2001; Underwood \& Fisher 2006). Sampling was done from 2003 to 2005 and again in 2009. The optimum workforce needed for the field work of a single $2000 \mathrm{~m}^{2}$ area was found to be four people, which is similarly labour intensive to other monitoring projects in SANParks (Figure 2). The total time spent sampling and identifying ants on a single plot was $460 \mathrm{~min}$, including $80 \mathrm{~min}$ spent on setting and removing traps, $80 \mathrm{~min}$ for screening an average of 300 individual ants, and $300 \mathrm{~min}$ for identifying them to species level under the microscope. Although comparatively inexpensive (see below), ant sampling was found to be more time consuming than other monitoring projects in the KNP (Figure 2). This may be mitigated by constantly using the same trained assistants and applying simplified assessments such as those developed for Australia (Andersen et al. 2002). The resources required for postcollection sorting, identification, curation and analyses are often not carefully considered and these are all critical for the collection and long-term use and storage of monitoring information. Considered per appropriate sample area, ant monitoring was also found to be one of the least expensive monitoring projects in the KNP (Figure 2).

Ants have been demonstrated to provide particularly valuable management-based information across a range of regions of the world, in particular for invasive species monitoring, detecting trends in functionally important species and those of specific conservation concern and assessing long-term changes in ecosystems and the consequences of management action (Underwood \& Fisher 2006). This series of factors makes the Formicidae particularly suitable for inclusion in PA monitoring systems in South Africa. 


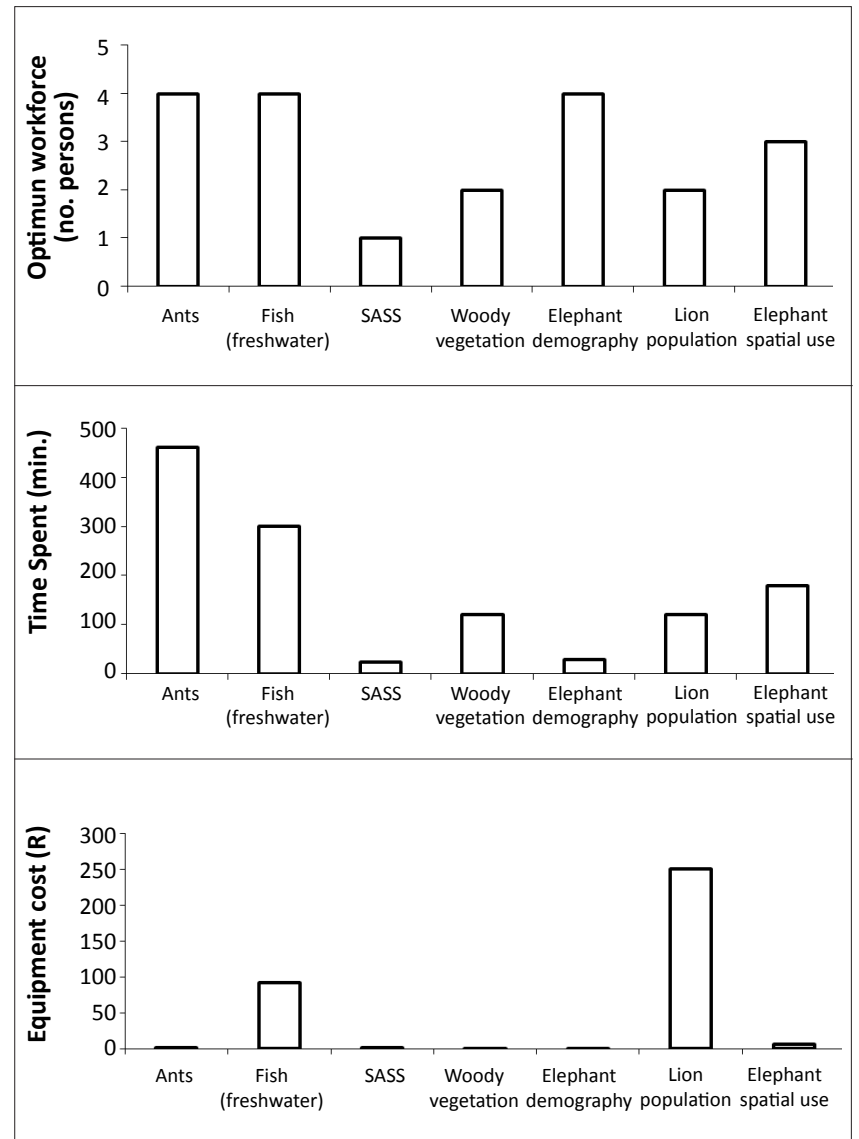

FIGURE 2: Estimated total resource costs per unit sampling area of the ant monitoring project in the Kruger National Park compared with six other monitoring projects in SANParks (different area for each project, but the minimum relevant unit area is used in each case).

\section{Selection of habitats for monitoring}

An alternative to selecting particular taxa is the selection of particular habitats as the focus for invertebrate monitoring (Dennis, Shreeve \& Sheppard 2007; see Samways [1993a] for a conceptual framework). The rationale for this approach may be either to conduct monitoring across a range of representative habitat types or to focus on particularly threatened or sensitive (priority) habitat types known to support unique assemblages of invertebrates and/or other taxa (New 1995). Systems and habitats worth monitoring will in many cases vary across PAs, as a result of biomespecific ecosystem characteristics. Component species and communities in such habitats may then be given weightings based on rarity, threat, endemism and phylogenetic uniqueness (Balmford, Jayasuriya \& Green 1996; Bonn, Rodrigues \& Gaston 2002; Davis 2002; Kier et al. 2009). The advantage of a habitat-based approach is that a clear association of habitat and critical elements of biodiversity can serve to prioritise a system worth investing in for long-term monitoring. The habitat can then be monitored for threats such as invasive species, climate change and water quality change. Initial monitoring will form a baseline against which future changes in species composition can be compared and indicator taxa may be used to monitor responses to environmental change (Botes et al. 2006a,b; Davis 2002; McGeoch et al. 2002; Rösch, Chown \& McGeoch 2001; Uys et al. 2010).
An example of habitat-focused monitoring is the streams in the TMNP. Because of the evolutionary significance and high levels of endemism, both streams and their associated Gondwanan biota could be prioritised for monitoring. Further reasons for doing so include the fact that Gondwanan taxa tend to be stenothermal (cold-adapted) (McKie, Cranston \& Pearson 2004) and thus are most at risk from elevated temperatures and the synergistic influence of reduced precipitation predicted by models of global warming for the Western Cape (De Wit \& Stankiewicz 2006). Baseline data for future monitoring in this habitat would include a thermal and biotic profile of a selected stream, encompassing both spatial (longitudinal stream profile) and seasonal variability. Against this baseline, future monitoring would then be conducted to detect the influences of climate change on both water temperature and invertebrate biota. Because water temperature is also influenced by flow, monitoring would simultaneously provide a baseline against which effects of the possible abstraction of the Table Mountain aquifer on the stream and its biota can be assessed. A year's worth of baseline data have already been collected for this project at Window Gorge Stream (Ketley 2009) and the project has been transferred to SANParks for future monitoring. Regular, ongoing monitoring is essential in this system if trends in change drivers (especially changing flow rates, water temperatures and biotic responses) are to be captured.

Both temporal and small-scale turnover, as well as habitat association, are generally poorly understood in invertebrate communities (Lovell et al.2010) and would need to be carefully considered in establishing and maintaining a habitat-based or community-based monitoring programme. For example, turnover of epigaeic invertebrates in Afrotemperate forest in the Drakensberg ranged from complete to $50 \%$, even in forests within the same valley (Hamer \& Slotow 2009; Uys, Hamer \& Slotow 2009). Similarly, temporal turnover between seasons and years may be high for epigaeic invertebrates and flying insects, particularly (Lovell et al. 2010).

\section{Conclusion}

We have shown that there are already several examples in South Africa of invertebrates (1) being successfully inventoried, (2) having their conservation status assessed, (3) being used in conservation planning, and (4) being used as bioindicators in monitoring programmes. Furthermore, a significant component of such activity has taken place in PAs. Generally such programmes focus on taxa that are well studied and readily identifiable and which are responsive to the variable under consideration or appropriate to the PA management objective. Nonetheless, for invertebrate information to be relevant to PA management, it is best linked explicitly to one or more management objectives for the PA in question (Walker \& Salt 2006).

Importantly, sufficient information and support are now available for particular taxa to be included practically in monitoring in PAs, and in many instances significant levels of endemism render invertebrates important for monitoring in their own right. Indeed, several current initiatives are set to improve this situation substantially. Good data on species 
richness, species distributions and population trends remain essential if invertebrates are to be considered in conservation management decisions and if effectiveness of these decisions for their protection is to be assessed. Currently such data are available for only a few key taxa.

The South African Biosystematics Initiative of the National Research Foundation currently provides some funding for invertebrate survey and monitoring research, if projects are well justified and placed in an appropriate conceptual framework. Significant opportunities thus exist to develop collaborations between PA agencies needing data and researchers skilled to provide these data. Collaboration between PA and external researchers on PA invertebrate research can produce valuable baseline data, taxonomic knowledge and inventories, which then enable PAs to (1) integrate invertebrates into PA monitoring programmes in a feasible manner and (2) continue key invertebrate monitoring in the longer term.

\section{Recommendations}

The following points serve as general recommendations:

- Although invertebrates are relevant and important across a range of PA management objectives, they should be explicitly and clearly linked to these objectives.

- Monitoring activities that involve invertebrates should focus on taxonomically well-known groups that are supported by, for example, good keys, available expertise and published evidence of their value in the specific context. The success of initiatives such as SANSA, Iimbovane and SABCA illustrates the feasibility and value of invertebrate surveys and monitoring in PAs.

- An important point to communicate to conservation planners is that vegetation or other surrogates do not adequately capture invertebrate diversity and that setting targets without considering at least some invertebrates is unlikely to capture invertebrate diversity (e.g. Hamer \& Slotow 2009).

- In a South African PA context, dragonflies, ants, butterflies and dung beetles (and increasingly also spiders) are appropriate for monitoring a broad range of management objectives.

- Invertebrate species of special concern represent a particular knowledge gap for PAs and here research is required to identify localised endemics and threatened species along with surveys targeting potentially important areas and taxa. For threatened species, some idea of habitat requirements and basic biology is required for adequate management, as well as approaches to monitoring threatened invertebrate species.

- Similarly, surveys of invasive alien invertebrate species are required along with research on their impacts and approaches to prevent further introductions.

- Profiling of invertebrates and training specialist invertebrate consultants are required to successfully integrate invertebrate conservation into processes legislated by NEMA and its subsidiary Acts. This will allow invertebrates to be explicitly considered and conserved in areas subject to change in land use.
- Collaborative relationships between entomologists, particularly systematists, and PA agencies should be fostered to maximise both research opportunities and opportunities to improve our knowledge of the invertebrate fauna of PAs. Citizen scientists continue to make an extremely valuable contribution to invertebrate surveys and monitoring in South Africa and their potential role in PA monitoring is significant.

\section{Acknowledgements}

This manuscript arose from a workshop on the use of invertebrates in monitoring in PAs, followed by a symposium on this theme at the 16th Congress of the Entomological Society of Southern Africa (Stellenbosch, July 2009). The authors thank the pioneers of mainstreaming invertebrate conservation in KwaZulu-Natal, the IEM team at Ezemvelo KZN Wildlife, Sharon Louw, John Craigie, Peter Goodman and colleagues, and Rachel Ndlovu for assistance with obtaining information from IEM case studies. Cost estimates for fish, lion, elephant and woody vegetation monitoring projects in SANParks were kindly provided by SANParks staff Sam Ferreira, Hugo Bezuidenhout and Ian Russell. We also thank two anonymous reviewers for their helpful comments. The National Research Foundation, Andrew W. Mellon Foundation and DST-NRF Centre for Invasion Biology are acknowledged for financial support.

\section{References}

Andersen, A.N., Hoffmann, B.D., Müller, W.J. \& Griffiths, A.D., 2002, 'Using ants as bioindicators in land management: Simplifying assessment of ant community
responses', Journal of Applied Ecology 39, 8-17. doi:10.1046/j.1365responses', Journal
2664.2002.00704.x

Andersen, A.N. \& Majer, J.D., 2004, 'Ants show the way Down Under: invertebrates as bioindicators in land management', Frontiers in Ecology \& Environment 2, 291-298. doi:10.1890/1540-9295(2004)002[0292:ASTWDU]2.0.CO;2

Armstrong, A.J., 2002, 'Insects and the determination of priority areas for biodiversity conservation in KwaZulu-Natal province, South Africa', African Entomology 10, 11-27.

Armstrong, A.J. \& Louw, S., 2010, 'KZN Biodiversity Status Assessment Report: Millar's tiger moth, Callioratis millari', Ezemvelo KZN Wildlife Report, Pietermaritzburg.

Balmford, A., Jayasuriya, A.H.M. \& Green, M.J.B., 1996, 'Using higher-taxon richness as a surrogate for species richness: II Local adaptations', Proceedings of the Royal Society of London B 263, 1571-1575. doi:10.1098/rspb.1996.0230, doi:10.1098/ rspb.1996.0186

Bonn, A., Rodrigues, A.S.L. \& Gaston, K.J., 2002, 'Threatened and endemic species: are they good indicators of patterns of biodiversity on a national scale?', Ecology Letters 5, 733-741. doi:10.1046/j.1461-0248.2002.00376.x

Botes, A., McGeoch, M.A. \& Van Rensburg B.J., 2006a, 'Elephant- and humaninduced changes to dung beetle (Coleoptera: Scarabaeidae) assemblages in the Maputaland Centre of Endemism', Biological Conservation 130, 573-583. doi:10.1016/j.biocon.2006.01.020

Botes, A., McGeoch, M.A., Robertson, H.G., Van Niekerk, A., Davids, H.P. \& Chown, S.L., 2006b, 'Ants, altitude and change in the northern Cape Floristic Region', Journal of Biogeography 33, 71-90. doi:10.1111/j.1365-2699.2005.01336.x

Braack, L. \& Kryger, P., 2003, 'Insects and savannah heterogeneity', in J.T. du Toit, K.H. Rogers \& H.C. Biggs (eds.), The Kruger experience, pp. 263-275, Island Press, London.

Braschler, B., 2009, 'Successfully implementing a citizen-scientist approach to insect monitoring in a resource-poor country', BioScience 59, 103-104. doi:10.1525/ bio.2009.59.2.2

Braschler, B., Mahood, K., Karenyi, N., Gaston, K.J. \& Chown, S.L., 2010, 'Realizing a synergy between research and education: How participation in ant monitoring
helps raise biodiversity awareness in a resource-poor country', Journal of Insect Conservation 14, 19-30. doi:10.1007/s10841-009-9221-6

Chovanec, A., 2000, 'Dragonflies (Insecta: Odonata) as indicators of the ecological integrity of aquatic systems - a new assessment approach', Verhandlungen der Internationalen Vereiningung für Theoretische und Angewandte Limnologie 27, 887-890.

Chown, S.L., Scholtz, C.H., Klok, C.J., Joubert, F.J. \& Coles, K.S., 1995, 'Ecophysiology, range contraction and survival of a geographically restricted African dung beetle (Coleoptera, Scarabaeidae)', Functional Ecology 9, 30-39. doi:10.2307/2390087 
Conrad, K.F., Fox, R. \& Woiwod, I.P., 2007, 'Monitoring biodiversity: Long-term changes in insect abundance', in A.J. Stewart, T.R. New \& O.T. Lewis (eds.) Insect conservation in insect abundance', in A.J. Stewart, T.R. New \& O.T. Lewis(eds.), Insect conser
biology, pp. 203-225, CABI, Wallingford. doi:10.1079/9781845932541.020

Cottrell, C.B., 1985, 'The absence of coevolutionary associations with Capensis floral element plants in the larval/plant relationships of southwestern Cape butterflies', Transvaal Museum Monographs 4, 115-124.

DACEL, 2003, A conservation plan for Gauteng, Gauteng Department of Agriculture, Conservation, Environment and Land Affairs, Johannesburg.

Dallas, H.F., 2007, 'The influence of biotope availability on macroinvertebrate assemblages in South African rivers: implications for aquatic bioassessment', Freshwater Biology 52, 370-380. doi:10.1111/j.1365-2427.2006.01684.x

Dallas, H.F., 2008, 'Water temperature and riverine ecosystems: An overview of knowledge and approaches for assessing biotic responses, with special reference to South Africa', Water SA 34, 393-404.

Dallas, H.F. \& Day, J.A., 1993, The effect of water quality variables on riverine ecosystems: A review, Technical Report Series No. TT 61/93, South Africa, Water Research Commission, Pretoria.

Damgaard, J., Klass, K-D., Picker, M.D. \& Buder, G., 2008, 'Phylogeny of the Heelwalkers (Insecta: Mantophasmatodea) based on mtDNA sequences, with evidence for additional taxa in South Africa', Molecular Phylogenetics and Evolution 47, 443-462. doi:10.1016/j.ympev.2008.01.026, PMid:18396416

Daniels, S.R., Picker, M.D., Cowling, R.M. \& Hamer, M., 2009, 'Unravelling evolutionary lineages among South African velvet worms (Onychophora: Peripatopsis) Evidence for cryptic species complexes', Biological Journal of the Linnean Society Evidence for cryptic species complexes', Biological Journ

Davis, A.L.V., 2002, 'Dung beetle diversity in South Africa: Influential factors, conservation status, data inadequacies and survey design', African Entomology $10,53-65$.

Day, B., 2005, 'The distribution of the palaeorelictual invertebrate fauna of South Africa', Report for Table Mountain Fund (Project number ZA 5061), WWF, Cape Town.

De Kock, A.E. \& Giliomee, J.H., 1989, 'A survey of the Argentine ant, Iridomyrmex humilis (Mayr), (Hymenoptera: Formicidae) in South African Fynbos', Journal of the Entomological Society of Southern Africa 52, 157-164.

De Kock, K.N. \&. Wolmarans, C.T., 2008, 'Invasive alien freshwater snail species in the Kruger National Park, South Africa', Koedoe 50, 49-53.

De Wit, M. \& Stankiewicz, J., 2006, 'Changes in surface water supply across Africa with predicted climate change', Science 311, 1917-1921. doi:10.1126/ science.1119929, PMid:16513946

Dennis, R.L.H., Shreeve, T.G. \& Sheppard, D.A., 2007, 'Species conservation and landscape management: A habitat perspective', in A.J. Stewart, T.R. New \& O.T. Lewis (eds.), Insect Conservation Biology, pp. 92-126, CABI, Wallingford.

Dippenaar-Schoeman, A.S., 1988, 'Annotated check list of the spiders (Araneae) of the Mountain Zebra National Park', Koedoe 31, 151-160.

Dippenaar-Schoeman, A.S., 2002, Baboon and trapdoor spiders of Southern Africa: An identification manual, Plant Protection Research Institute Handbook 13, Agricultural Research Council, Pretoria.

Dippenaar-Schoeman, A.S., 2006, 'New records of 43 spider species from the Mountain Zebra National Park, South Africa (Arachnida: Araneae)', Koedoe 49, 23-28.

Dippenaar-Schoeman, A.S. \& Leroy, A., 2003, 'A check list of the spiders of the Kruger National Park, South Africa (Arachnida: Araneae)', Koedoe 46, 91-100.

Dippenaar-Schoeman, A.S., Leroy, A., De Jager, M. \& Van den Berg, A., 1999, 'Spider diversity of the Karoo National Park, South Africa (Arachnida: Araneae)', Koedoe $42,31-42$.

Dippenaar-Schoeman, A.S., Van der Walt, A.E., Le Roux, E. \& Van den Berg, A., 2005, 'The spiders of the Swartberg Nature Reserve in South Africa (Arachnida: Araneae)', Koedoe 48, 77-86.

Dobson, A., 2005, 'Monitoring global rates of biodiversity change: Challenges that arise in meeting the Convention on Biological Diversity (CBD) 2010 goals', Philosophical Transactions of the Royal Society London B 360, 229-241. doi:10.1098/rstb.2004.1603, PMid:15814342, PMCid:1569458

Driver, A., Maze, K., Rouget, M., Lombard, A.T., Nel, J., Turpie, J.K., et al., 2005, National spatial biodiversity assessment 2004: Priorities for biodiversity conservation in South Africa, Strelitzia 17, South African National Biodiversity Institute, Pretoria.

Droege, S., Cyr, A. \& Larivée, J., 1998, 'Checklists: An under-used tool for the inventory and monitoring of plants and animals', Conservation Biology 12, 1134-1138. and monitoring of plants and animals',

Edge, D.A., 2005, 'Butterfly conservation in the southern Cape', Metamorphosis 16, $28-46$.

Engelbrecht, I.A., 2010, 'Invertebrate species inventories in protected area management: are they useful?', African Entomology 18, 235-245. doi:10.4001/003.018.0203

Forsyth, G. \& Van Wilgen, B., 2008, 'The recent fire history of Table Mountain National Park and implications for fire management', Koedoe 50, 3-9.

Goodman, P.S., 2000, 'Determining the conservation value of land in KwaZulu-Natal', Final report, KwaZulu-Natal Nature Conservation Service, Pietermaritzburg.

Grimaldi, D. \& Engel, M.S., 2005, Evolution of the insects, Cambridge University Press, Cambridge.

Haddad, C.R., Dippenaar-Schoeman, A.S. \& Wesołowska, W., 2006, 'A checklist of the non-acarine arachnids (Chelicerata: Arachnida) of the Ndumo Game Reserve, Maputoland, South Africa', Koedoe 49, 1-22.

Hamer, M.L., 1998, 'Checklist of southern African millipedes', Annals of the Natal Museum 39, 11-82.

Hamer, M.L. \& Slotow, R.H., 2002, 'Conservation application of existing data for South African millipedes (Diplopoda)', African Entomology 10, 29-42.
Hamer, M. \& Slotow, R., 2009, 'A comparison and conservation assessment of the high-altitude grassland and forest-millipede (Diplopoda) fauna of the South African Drakensberg', Soil Organisms 81, 701-717.

Hamer, M.L., Samways, M.J. \& Ruhberg, H., 1997, 'A review of the Onychophora of South Africa, with discussion of their conservation', Annals of the Natal Museum 38, 283-312.

Hamer, M.L., Slotow, R.H. \& Lovell, S., 2006, 'The South African savanna millipede (Diplopoda) fauna: Taxonomic diversity, endemism and spatial and temporal effects on conservation assessments', Norwegian Journal of Entomology 53, effects on

Hanski, I. \& Pöyry, J., 2007, 'Insect populations in fragmented habitats', in A.J. Stewart, T.R. New \& O.T. Lewis (eds.), Insect conservation biology, pp. 175-202, CABI, Wallingford. doi:10.1079/9781845932541.0175

Henning, S.F. \& Henning, G.A., 1989, 'South African Red Data Book: Butterflies', South African National Scientific Program Report No. 158, Foundation for Research Development, Pretoria.

Henning, G.A., Terblanche, R.F. \& Ball, J.B. (eds.), 2009, South African Red Data Book: Butterflies, South African National Biodiversity Institute, Pretoria.

Herbert, D. \& Kilburn, D., 2004, Field guide to the land snails and slugs of eastern South Africa, Natal Museum, Pietermaritzburg.

Horn, J.L., Plisko, J.D. \& Hamer, M.L., 2007, 'The leaf-litter earthworm fauna (Annelida: Oligochaeta) of forests in Limpopo Province, South Africa: diversity, communities and conservation', African Zoology 42, 172-179. doi:10.3377/15627020(2007)42[172:TLEFAO]2.0.CO;2

Kaspari, M. \& Majer, J.D., 2000, 'Using ants to monitor environmental change', in D. Agosti, J.D. Majer, L.E. Alonso \& T.R. Schultz (eds.), Ants: Standard methods for measuring and monitoring biodiversity, pp. 89-98, Smithsonian Institution Press, measuring and
Washington DC.

Kenis, M., Auger-Rozenberg, M.-A., Roques, A., Timms, L., Péré, C., Cock, M.J.W., et al., 2009 ,' 'Ecological effects of invasive alien insects', Biological Invasions 11, 21-45. doi:10.1007/s10530-008-9318-y

Ketley, Z.A., 2009, 'Stream invertebrates and water temperature: evaluating thermal tolerances in the Cape Floristic Region (South Africa) - implications of climate change', MSc thesis, Dept. of Zoology, University of Cape Town.

Kier, G., Kreft, H., Lee, T.M., Jetz, W., Ibisch, P.I., Nowicki, C., et al., 2009, 'A global assessment of endemism and species richness across island and mainland regions', Proceedings of the National Academy of Sciences of the United States of America 106, 9322-9327. doi:10.1073/pnas.0810306106, PMid:19470638, PMCid:2685248

Koch, S.O., Chown, S.L., Davis, A.L.V., Endrödy-Younga, S. \& Van Jaarsveld, A.S., 2000, 'Conservation strategies for poorly surveyed taxa: A dung beetle (Coleoptera, 45-56. doi:10.1023/A:1009634318926

Kremen, C., Colwell, R.K., Erwin, T.L., Murphy, D.D., Noss, R.F. \& Sanjayan, M.A., 1993, 'Terrestrial arthropod assemblages: Their use in conservation planning', Conservation Biology 7, 796-808. doi:10.1046/j.1523-1739.1993.740796.x

Lawrence, R.F., 1953, The biology of the cryptic fauna of forests. With special reference to the indigenous forests of South Africa, A.A. Balkema, Cape Town.

Losey, J.E. \& Vaughan, M., 2006, 'The economic value of ecological services provided by insects', Bioscience 56, 311-323. doi:10.1641/0006-3568(2006)56[311:TEVOE S]2.0.CO;2

Lovell, S., Hamer, M., Slotow, R. \& Herbert, D., 2007, 'Assessment of congruency across invertebrate taxa and taxonomic levels to identify potential surrogates', Biological Conservation 139, 113-125. doi:10.1016/j.biocon.2007.06.008

Lovell, S., Hamer, M., Slotow, R. \& Herbert, D., 2010, 'Assessment of sampling approaches for a multi-taxa invertebrate survey in a South African savanna-mosaic ecosystem', Austral Ecology 35, 357-370. doi:10.1111/j.1442-9993.2009.02052.x

Lowe, S., Browne, M., Boudjela, S. \& De Poorter, M., 2000, '100 of the world's worst invasive alien species. A selection from the Global Invasive Species database', The Invasive Species Specialist Group (ISSG), IUCN, Gland.

Lyons, C., Picker, M.D. \& Carrick, P., 2008, 'Evaluating restoration success of alluvial diamond-mined sites using invertebrate community indicators', Mine Closure Proceedings 3, 821-830.

Macdonald, I.A.W., Reaser, J.K., Bright, C., Neville, L.E., Howard, G.W., Murphy, S.J., et al. (eds.), 2003, 'Invasive alien species in southern Africa: National reports \& directory of resources', Global Invasive Species Programme, Cape Town.

McGeoch, M.A., 1998, 'The selection, testing and application of terrestrial insects as bioindicators', Biological Reviews 73, 181-201. doi:10.1017/S000632319700515X, doi:10.1111/j.1469-185X.1997.tb00029.x

McGeoch, M.A., 2002, 'Insect conservation in South Africa: An overview', African Entomology 10, 1-10.

McGeoch, M.A., 2007, 'Insects and bioindication: Theory and practice', in A.J. Stewart, T.R. New \& O.T. Lewis (eds.), Insect conservation biology, pp. 144-174, CABI, Wallingford. doi:10.1079/9781845932541.0144

McGeoch, M.A., Van Rensburg, B.J. \& Botes, A., 2002, 'The verification and application of bioindicators: A case study of dung beetles in a savanna ecosystem', Journal of Applied Ecology 39, 661-672. doi:10.1046/j.1365-2664.2002.00743.x

McGeoch, M.A., Le Roux, P.C., Hugo, A.E. \& Chown, S.L., 2006, 'Species and community responses to short-term climate manipulation: Microarthropods in the subAntarctic', Austral Ecology 31, 719-731. doi:10.1111/j.1442-9993.2006.01614.x

McGeoch, M.A., Dopolo, M., Novellie, P., Hendriks, H., Freitag, S., Ferreira, S., et al., 2011, 'A strategic framework for biodiversity monitoring in SANParks', Koedoe 53(2), Art. \#991, 10 pages. doi:10.4102/koedoe.v53i2.991

McKie, B.G., Cranston, P.S. \& Pearson, R.G., 2004, 'Gondwanan mesotherms and cosmopolitan eurytherms: Effects of temperature on the development and survival of Australian Chironomidae (Diptera) from tropical and temperate populations', Marine \& Freshwater Research 55, 759-768. doi:10.1071/MF04023

Mound, L.A. \& Gaston, K.J., 1993, 'Conservation and systematics - the agony and the ecstasy', in K.J. Gaston, T.R. New \& M.J. Samways (eds.), Perspectives on insect conservation, pp. 185-196, Intercept, Andover. 
Nel, J.L., Roux, D.J., Maree, G., Kleynhans, C.J., Moolman, J., Reyers, B., et al., 2007, 'A systematic conservation assessment of the ecosystem status and protection
levels of main rivers in South Africa', Diversity and Distributions 13, 341-352. levels of main rivers in South Africa',
doi:10.1111/j.1472-4642.2007.00308.x

New, T.R., 1995, An introduction to invertebrate conservation biology, Oxford University Press, Oxford.

New, T.R., 1998, Invertebrate surveys for conservation, Oxford University Press, Oxford.

Odendaal, L.J., Haupt, T.M. \& Griffiths, C.H., 2008, 'The alien invasive land snail Theba pisana in the West Coast National park: Is there cause for concern?', Koedoe 50, 93-98.

Panzer, R. \& Schwartz, M.W., 1998, 'Effectiveness of a vegetation-based approach to insect conservation', Conservation Biology 12, 693-702. doi:10.1046/j.1523to insect conservation
$1739.1998 .97051 . x$

Parr, C.L. \& Chown, S.L., 2001, 'Inventory and bioindicator sampling: Testing pitfall and Winkler methods with ants in a South African savanna', Journal of Insect Conservation 5, 27-36. doi:10.1023/A:1011311418962

Parr, C.L., Bond, W.J. \& Robertson, H.G., 2002, 'A preliminary study of the effect of fire on ants (Formicidae) in a South African savanna', African Entomology 10, 101-111.

Parr, C.L., Robertson, H.G., Biggs, H.C. \& Chown, S.L., 2004, 'Response of African savanna ants to long-term fire regimes', Journal of Applied Ecology 41, 630-642. doi:10.1111/j.0021-8901.2004.00920.x

Picker, M.D. \& Samways, M.J., 1996, 'Faunal diversity and endemicity of the Cape Peninsula, South Africa - a first assessment', Biodiversity and Conservation 5, 591-606. doi:10.1007/BF00137611

Prendini, L., 2005, 'Scorpion diversity and distribution in southern Africa: Pattern and process', in B.A. Huber, B.J. Sinclair \& K.-H. Lampe (eds.), African Biodiversity: Molecules, Organisms, Ecosystems, pp. 25-28, Springer, Amsterdam.

Pringle, E.L.L., Henning, G.A., \& Ball, J.B., 1994, Pennington's Butterflies of Southern Africa, 2nd edn., Struik Winchester, Cape Town.

Procheş, S., Forest, F., Veldtman, R., Chown, S.L., Cowling, R.M., Johnson, S.D., et al., 2009, 'Dissecting the plant-insect diversity relationship in the Cape', Molecular 2009, 'Dissecting the plant-insect divers.
Phylogenetics and Evolution 51(1), 94-99.

Pryke, J.S., 2008, 'Conservation of invertebrate fauna of the Cape Peninsula', PhD thesis, Dept. of Conservation Ecology and Entomology, Stellenbosch University.

Pryke, J.S. \& Samways, M.J., 2008, 'Conservation of invertebrate biodiversity on a mountain in a global biodiversity hotspot, Cape Floral Region', Biodiversity and Conservation 17, 3027-3043. doi:10.1007/s10531-008-9414-4

Pryke, J.S. \& Samways, M.J., 2009a, 'Conservation of the insect assemblages of the Cape Peninsula biodiversity hotspot', Journal of Insect Conservation 13, 627-641. doi:10.1007/s10841-009-9213-6

Pryke, J.S. \& Samways, M.J., 2009b, 'Recovery of invertebrate diversity in a rehabilitated city landscape mosaic in the heart of a biodiversity hotspot', Landscape and Urban Planning 93, 54-62. doi:10.1016/j.landurbplan.2009.06.003

Pryke, J.S. \& Samways, M.J., 2010, 'Significant variables for the conservation of mountain invertebrates', Journal of Insect Conservation 14, 247-256. doi:10.1007/ s10841-009-9253-y

Raharinjanahary, D., 2007, 'Impact of Argentine ants (Linepithema humile Mayr) on saproxylic invertebrates in Afromontane forest and pine plantation of the Cape Peninsula (South Africa)', MSc thesis, Dept. of Zoology, University of Cape Town.

Revenga, C., Campbell, I., Abell, R., De Villiers, P. \& Bryer, M., 2005, 'Prospects for monitoring freshwater ecosystems towards the 2010 targets', Philosophical Transactions of the Royal Society of London B 360, 397-413. doi:10.1098/
rstb.2004.1595, PMid:15814353, PMCid:1569454

Rohr, J.R., Kim, K. \& Mahan, C., 2007, 'Developing a monitoring program for invertebrates: Guidelines and a case study', Conservation Biology 21, 422-433. doi:10.1111/j.1523-1739.2006.00578.x, PMid:17391192

Rösch, M., Chown, S.L. \& McGeoch, M.A., 2001, 'Testing a bioindicator assemblage: Gall-inhabiting moths and urbanization', African Entomology 9, 85-94.

Samways, M.J., 1993a, 'A spatial and process sub-regional framework for insect and biodiversity conservation research and management', in K.J. Gaston, T.R. New \& M.J. Samways (eds.), Perspectives on insect conservation, pp. 1-28, Intercept, Andover.

Samways, M.J., 1993b, 'Dragonflies (Odonata) in taxic overlays and biodiversity conservation', in K.J. Gaston, T.R. New \& M.J. Samways (eds.), Perspectives on conservation', in K.J. Gaston, T.R. New \& M.J. Samw
insect conservation, pp. 111-124, Intercept, Andover.

Samways, M.J., 2005, Insect diversity conservation, Cambridge University Press, Cambridge. doi:10.1017/СВ09780511614163

Samways, M.J., 2006, 'National Red List of South African Odonata', Odonatologica 35, 341-368.

Samways, M.J., 2008, Dragonflies and damselflies of South Africa, Pensoft, Sophia.

Samways, M.J. \& Sharratt, N.J., 2010, 'Recovery of endemic dragonflies after removal of invasive alien trees', Conservation Biology 24, 267-277. doi:10.1111/j.15231739.2009.01427.x, PMid:20121847

Samways, M.J., McGeoch, M.A. \& New, T.R., 2010, Insect conservation: A handbook of approaches and methods, Oxford University Press, Oxford.

Scholes, R.J. \& Walker, B.H., 1993, An African savanna: Synthesis of the Nylsvley study, Cambridge University Press, Cambridge. doi:10.1017/СBO978051156547

Scholtz, C.H. \& Chown, S.L., 1993, 'Insect conservation and extensive agriculture: the savanna of southern Africa', in K.J. Gaston, T.R. New \& M.J. Samways (eds.), Perspectives on insect conservation, pp. 75-96, Intercept, Andover.

Scholtz, C.H. \& Chown, S.L., 1995, 'Insects in southern Africa: How many species are there?', South African Journal of Science 91, 124-126.

Scholtz, C.H. \& Holm, E., 1985, Insects of Southern Africa, Butterworths, Durban.

Sharratt, N.J., Picker, M.D. \& Samways, M.J., 2000, 'The invertebrate fauna of the sandstone caves of the Cape Peninsula (South Africa): Patterns of endemism
and conservation priorities', Biodiversity and Conservation 9, 107-143. doi:10.1023/A:1008968518058
Simaika, J.P. \& Samways, M.J., 2008, 'Valuing dragonflies as service providers', in A. Cordoba-Aguilar (ed.), Dragonflies: Model organisms for ecological and evolutionary research, pp. 109-123, Oxford University Press, Oxford.

Simaika, J.P. \& Samways, M.J., 2009a, 'An easy-to-use index of ecological integrity for prioritizing streams for conservation action', Biodiversity and Conservation 18, 1171-1185. doi:10.1007/s10531-008-9484-3

Simaika, J.P. \& Samways, M.J., 2009b, 'Reserve selection using Red Listed taxa in three global biodiversity hotspots: Dragonflies in South Africa', Biological Conservation 142, 638-651. doi:10.1016/j.biocon.2008.11.012

Simaika, J.P. \& Samways, M.J., 2011, 'Comparative assessment of indices of freshwater habitat conditions using different invertebrate taxon sets', Ecological Indicators 11, 370-378. doi:10.1016/j.ecolind.2010.06.005

Sithole, H., Smit, I.P.J. \& Parr, C.L., 2010, 'Preliminary investigations into a potential ant invader in Kruger National Park, South Africa', African Journal of Ecology 48, 736-743.

Smith, J., Samways, M.J. \& Taylor, S., 2007, 'Assessing riparian quality using two complementary sets of bioindicators', Biodiversity and Conservation 16, 2695-2713. doi:10.1007/s10531-006-9081-2

Speight, M.C.D. \& Castella, E., 2001, 'An approach to interpretation of lists of insects using digitised biological information about the species', Journal of Insect Conservation 5, 131-139. doi:10.1023/A:1011399800825

Stiller, M., 2002, 'Leafhopper (Hemiptera: Cicadellidae) diversity in the Fynbos Biome of South Africa', Denisia 4, 379-400.

Telford, M.J. \& Littlewood, D.T.J., 2008, 'The evolution of the animals: introduction to a Linnean tercentenary celebration', Philosophical Transactions of the Royal Society of London B 363, 1421-1424. doi:10.1098/rstb.2007.2231, PMid:18192193, PMCid:2394567

Thomas, J.A., 2005, 'Monitoring change in the abundance and distribution of insects using butterflies and other indicator groups', Philosophical Transactions of the Royal Society of London B 360, 339-357. doi:10.1098/rstb.2004.1585, of the Royal Society of London

Thompson, M.W., 2008, KZN Province Land-Cover Mapping (from SPOT 2 / 4 Satellite imagery 2005-2006), Data Users Report and Meta Data (version 2.0), GeoTerralmage, Pretoria.

Underwood, E.C. \& Fisher, B.L., 2006, 'The role of ants in conservation monitoring: If, when, and how', Biological Conservation 132, 166-182. doi:10.1016/j. biocon.2006.03.022

Uys, C., Hamer, M. \& Slotow, R., 2006, 'The effect of burn area on invertebrate recolonisation in grasslands in the Drakensberg, South Africa', African Zoology 41, 51-65. doi:10.3377/1562-7020(2006)41[51:EOBAOI]2.0.CO;2

Uys, C., Hamer, M. \& Slotow, R., 2009, 'Turnover in invertebrate species composition over different spatial scales in Afrotemperate forest in the Drakensberg, South Africa', African Journal of Ecology 47, 341-351. doi:10.1111/j.13652028.2008.00968.x

Uys, C., Hamer, M. \& Slotow, R., 2010, 'Step process for selecting and testing surrogates and indicators of Afrotemperate Forest invertebrate diversity', PLOS ONE 5(2), e9100. doi:10.1371/journal.pone.0009100, PMid:20161757, PMCid:2817749

Valéry, L., Fritz, H., Lefeuvre, J.-C. \& Simberloff, D., 2008, 'In search of a real definition of the biological invasion phenomenon itself', Biological Invasions 10, 1345-1351. doi:10.1007/s10530-007-9209-7

Vane-Wright, R.I., 1993, 'Systematics and the conservation of biodiversity: Global, national and local perspectives', in K.J. Gaston, T.R. New \& M.J. Samways (eds.), Perspectives on insect conservation, pp. 197-212, Intercept, Andover.

Veldtman, R., McGeoch, M.A. \& Scholtz, C.H., 2002, 'Variability in cocoon size in southern African wild silk moths: Implications for sustainable harvesting', African Entomology 10, 127-136.

Vilà, M., Basnou, C. \& Pyšek, P., Josefsson, M., Genovesi, P., Gollasch, S., et al., 2010, 'How well do we understand the impacts of alien species on ecosystem services? A pan-European, cross-taxa assessment', Frontiers in Ecology and the Environment 8, 135-144. doi:10.1890/080083

Walker, B. \& Salt, D., 2006, Resilience thinking: Sustaining ecosystems and people in a changing world, Island Press, Washington DC.

Warren, M.S., Bourn, N., Brereton, T., Fox, R., Middlebrook, I. \& Parsons, M.S., 2007, 'What have Red Lists done for us? The values and limitations of protected species listing for invertebrates', in A.J. Stewart, T.R. New \& O.T. Lewis (eds.), Insect conservation biology, pp. 76-91, CABI, Wallingford. doi:10.1079/9781845932541.0076

Wesołowska, W. \& Haddad, C.R., 2009, 'Jumping spiders (Araneae: Salticidae) of the Ndumo Game Reserve, Maputaland, South Africa', African Invertebrates 50, 13-103.

Wilson, R.J., Davies, Z.G. \& Thomas, C.D., 2007, 'Insects and climate change: Processes, patterns and implications for climate change', in A.J. Stewart, T.R. New \& O.T. Lewis OT (eds.), Insect conservation biology, pp. 245-279, CABI, Wallingford.

Wilson, J.R.U., Dormontt, E.E., Prentis, P.J., Lowe, A.J. \& Richardson, D.M., 2009, 'Something in the way you move: Dispersal pathways affect invasion success', Trends in Ecology and Evolution 24(3), 136-144. doi:10.1016/j.tree.2008.10.007

Woiwod, I.P. \& Harrington, R., 1994, 'Flying in the face of change: The Rothamsted Insect Survey', in R. Leigh \& A. Johnston (eds.), Long-term experiments in agricultural and ecological sciences, pp. 321-342, CAB International, Wallingford.

Woodroffe, R. \& Ginsberg, J.R., 1998, 'Edge effects and the extinction of populations inside protected areas', Science 280, 2126-2128. doi:10.1126/ science.280.5372.2126, PMid:9641920

Wright, M.G. \& Samways, M.J., 1998, 'Insect species richness tracking plant species richness in a diverse flora: Gall-insects in the Cape Floristic Region, South Africa', Oecologia 115, 427-433. doi:10.1007/s004420050537

Wright, J.F., Sutcliffe, D.W. \& Furse, M.T., 2000, Assessing the biological quality of fresh waters, The Freshwater Biological Association, Ambleside. 